\title{
Diversity and antibacterial activity of fungal endophytes from Eucalyptus exserta
}

Ziling Mao', Weihao Zhang ${ }^{1}$, Chunyin Wu', Hao Feng ${ }^{1}$, Yuanhang Peng ${ }^{1}$, Hamza Shahid', Zining Cui², Ping Ding ${ }^{3^{*}}$ and Tijiang Shan ${ }^{1^{*}}$

\begin{abstract}
Background: Eucalyptus bacterial wilt caused by Ralstonia solanacearum is an important eucalyptus disease. Endophytic fungi, an important source of natural active substances, provide a new breakthrough for the control of plant diseases.

Results: In the present study, 80 endophytic fungal isolates were obtained from the healthy branches and fruits of Eucalyptus exserta. Fifteen distinct isolates (MK120854-MK120868) were selected for further taxonomic identification through morphological trait assessments and internal transcribed spacer (ITS) region-rRNA gene sequence analysis. Thirteen genera, namely, Phyllosticta, Penicillium, Eutypella, Purpureocillium, Talaromyces, Lophiostoma, Cladosporium, Pestalotiopsis, Chaetomium, Fusarium, Gongronella, Scedosporium and Pseudallescheria, were identified on the basis of their morphological characteristics. Members of the genus Phyllosticta were the primary isolates, with a colonization frequency (CF) of $27.5 \%$. Most of the fungal isolates displayed antibacterial activity. The crude extracts obtained from Lophiostoma sp. Eef-7, Pestalotiopsis sp. Eef-9 and Chaetomium sp. Eef-10 exhibited strong inhibition on the test bacteria, and Lophiostoma sp. Eef-7 was further cultured on a large scale. Three known compounds, scorpinone (1), 5-deoxybostrycoidin (2) and 4-methyl-5,6-dihydro-2 $\mathrm{H}$-pyran-2-one (3), were isolated from the endophytic fungus Lophiostoma sp. Eef-7 associated with E. exserta. The structures of these compounds were elucidated by analysis of 1D and 2D NMR and HR-ESI-MS spectra and a comparison of their spectral data with published values. Compounds 1 and 2 showed weak antimicrobial activity against Ralstonia solanacearum.

Conclusions: Endophytic fungi from Eucalyptus exserta may represent alternative sources of antimicrobial agents. Lophiostoma sp. Eef-7 can produce 2-azaanthraquinone derivatives and shows weak antibacterial activity against Ralstonia solanacearum.
\end{abstract}

Keywords: Endophytic fungi, Eucalyptus exserta, Secondary metabolites, Antibacterial activity, Lophiostoma sp. Eef-7, Ralstonia solanacearum

\footnotetext{
*Correspondence: dingpinggz@126.com; tjshan@scau.edu.cn

${ }^{3}$ School of Pharmaceutical Sciences, Guangzhou University of Chinese

Medicine, No. 232, Waihuandong Road, Panyu District, Guangdong 510006 Guangzhou, China

${ }^{1}$ Guangdong Key Laboratory for Innovative Development and Utilization of Forest Plant Germplasm, College of Forestry and Landscape Architecture, South China Agricultural University, 510642, No. 483, Wushan Road, Tianhe District, Guangdong 510642 Guangzhou, China

Full list of author information is available at the end of the article
}

(c) The Author(s). 2021 Open Access This article is licensed under a Creative Commons Attribution 4.0 International License, which permits use, sharing, adaptation, distribution and reproduction in any medium or format, as long as you give appropriate credit to the original author(s) and the source, provide a link to the Creative Commons licence, and indicate if changes were made. The images or other third party material in this article are included in the article's Creative Commons licence, unless indicated otherwise in a credit line to the material. If material is not included in the article's Creative Commons licence and your intended use is not permitted by statutory regulation or exceeds the permitted use, you will need to obtain permission directly from the copyright holder. To view a copy of this licence, visit http://creativecommons.org/licenses/by/4.0/ The Creative Commons Public Domain Dedication waiver (http://creativecommons.org/publicdomain/zero/1.0/) applies to the data made available in this article, unless otherwise stated in a credit line to the data. 


\section{Background}

Eucalyptus bacterial wilt caused by Ralstonia solanacearum (Smith) Yabuuchi is a destructive, systemic vascular bundle disease referred to as cancer in eucalyptus. In recent years, this disease has been prevalent in South China and has become a major obstacle to the development of eucalyptus forests, severely threatening the sustainable development of the eucalyptus industry [1]. Plant diseases caused by pathogenic bacteria directly result in enormous losses in the agricultural economy each year and are significant issues that need to be resolved $[2,3]$. Currently, chemical pesticides such as antibiotics are some of the most efficient and cost-effective methods of controlling plant pathogenic bacteria. However, with the long-term use of pesticides in large quantities, the emergence of drug-resistant pathogenic bacterial strains has made this problem even more intractable [4]. In recent years, the extensive and frequently inappropriate use of antibiotics has caused pathogenic bacteria to develop resistance to commercial drugs. Consequently, the search for antibacterial substances with novel structures and outstanding bioactivity from natural products and developing them into commercial pesticides has become a research hotspot in agriculture [5].

Natural products such as medicines have likely been used by humans for thousands of years. These products are derived from natural sources such as microorganisms, plants or animals [6]. Plant endophytes are microorganisms that reside in the tissues of living plants without causing any apparent adverse effects to their host plants [7-9]. Endophytic fungi of plants are known as a feracious source of natural products with interesting bioactivities, such as antibacterial, larvicidal, antioxidant, anti-inflammatory, and phytotoxic activities [10-14]. In the past few years, an increasing number of active substances with unique chemical structures have been isolated from endophytic fungi using a combination of morphological, phylogenetic and metabolomics analyses $[15,16]$. From 1981 to 2010 , more than $50 \%$ of small molecules originated from natural products [17]. The main antibacterial, antifungal, antiviral and anticancer compounds came from natural sources such as plants, fungi, and even bacteria. These compounds have been isolated from previously studied plants, including bryophytes [18], pteridophytes [19], herbage [20] and angiosperms [21]. Most endophytic fungi produce bioactive secondary metabolites such as alkaloids, terpenoids, steroids, quinones, isocoumarins, lignans, phenylpropanoids, phenols, and lactones [22-24].

Eucalyptus exserta is a well-known Chinese afforestation tree species that is primarily distributed in South China and has leaves that produce essential oil with antimicrobial activities. To date, few studies have investigated endophytic fungi from E. exserta. As part of our ongoing investigation of endophytic fungi from $E$. exserta, which has been reported to have endophytes with antimicrobial activity, attracted our attention [25]. Thus, the goal of this present study was to isolate and identify endophytic fungi from $E$. exserta and to search for endophytic fungi capable of producing bioactive substances with antimicrobial activity. The isolation, structural elucidation, and antimicrobial activities of metabolites from a terrestrial Lophiostoma strain are reported for the first time.

\section{Results}

\section{Identification of the endophytic fungi}

In the present study, 80 fungal isolates were obtained from healthy branches and fruits of $E$. exserta. According to their morphological features, the isolates were preliminarily grouped through dereplication into fifteen different morphological taxa (Fig. 1) that were then selected for DNA sequence analysis using the ITS region. The ITS (ITS4-5.8 S-ITS5) sequences of these endophytic fungi were compared to corresponding reference fungal taxa sequences in GenBank. Based on the macro- and microscopic identification results, they were identified as members of thirteen genera, including Phyllosticta, Penicillium, Eutypella, Purpureocillium, Talaromyces, Lophiostoma, Cladosporium, Pestalotiopsis, Chaetomium, Fusarium, Gongronella, Scedosporium and Pseudallescheria (Table 1). The diversity of these fungi associated with $E$. exserta was revealed by evaluating their colonization frequency (CF). The fungi of the genus Phyllosticta were the primary isolates, with a CF of $27.5 \%$, followed by those of the genus Eutypella, with a CF of $10 \%$. The ITS4-5.8 S-ITS5 partial sequences of 15 isolates were submitted to GenBank to obtain accession numbers (MK120854 MK120868), and the closest related species were obtained by BLAST analysis (Table 1). The results showed that all the sequences had more than $98 \%$ similarity with the species in GenBank.

\section{Phylogenetic relationship analysis of the fungal endophytes}

The ITS sequence data of fifteen fungal endophytes from $E$. exserta were submitted to GenBank under the accession numbers MK120854 to MK120868 (Table 1), and sequence data of the closest related species were obtained from the same database. These datasets were used to construct a phylogenetic tree with the maximum likelihood method and analyze the phylogenetic affiliations of these endophytes (Fig. 2). The 15 fungal isolates could be sorted into 12 groups, Microascaceae, Ophiocordycipitaceae, Nectriaceae, Chaetomiaceae, Pestalotiopsidaceae, Diatrypaceae, Cladosporiaceae, Aspergillaceae, Trichocomaceae, Botryosphaeriaceae, Lophiostomataceae and Cunninghamellaceae, 


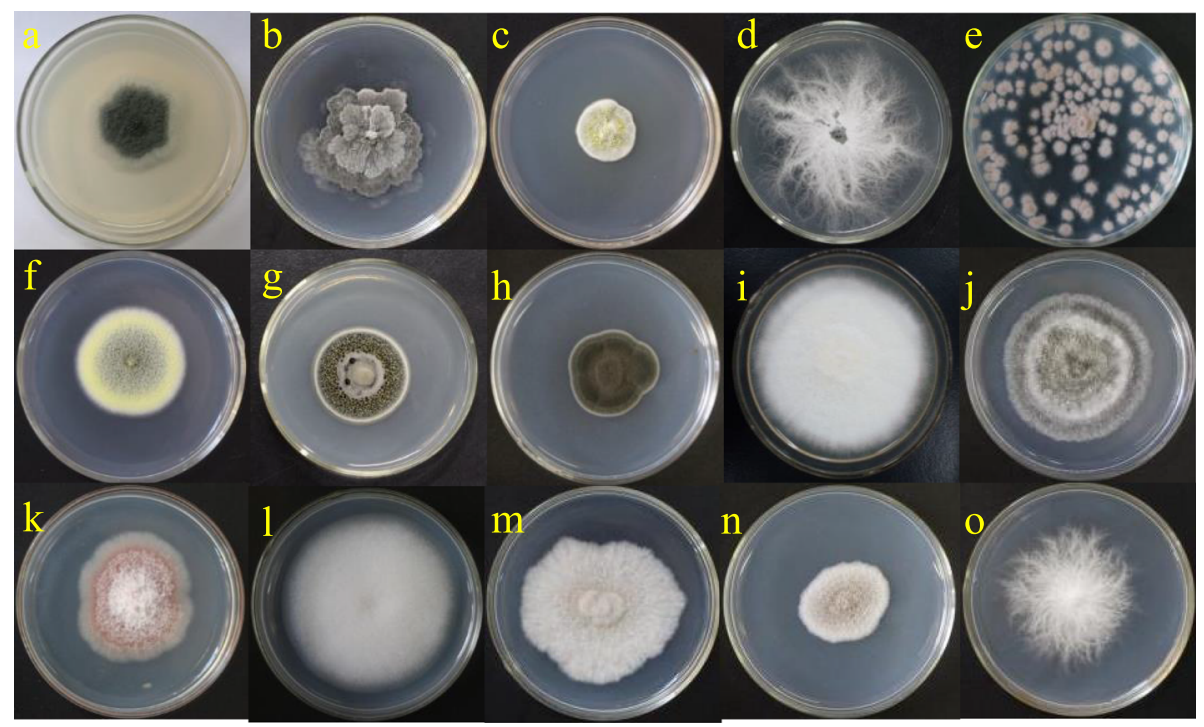

Fig. 1 Endophytic Fungi isolated from Eucalyptus exserta. a o were endophytic fungal isolates Eef-1 Eef-15, respectively

all of which belong to Ascomycota except for isolate Eef-12 (Gongronella sp.), which belongs to the phylum Zygomycota.

\section{Antimicrobial activity screening of EtOAc extracts from endophytic fungi}

The antibacterial activity results of the ethyl acetate (EtOAc) extracts from the endophytic fungi against seven test bacteria using a thin layer chromatography (TLC)-bioautography assay are shown in Table 2. The results showed that most of the EtOAc extracts displayed specific inhibitory activity, with a range of inhibitory activity observed against different tested bacteria. Some fungal isolates (e.g., Eef-6, Eef-9, Eef-10, Eef11 and Eef-12) displayed antibacterial activities against all tested bacteria. Eef-4 displayed antibacterial activities against six tested bacteria except for Xanthomonas vesicatoria. The EtOAc extracts of the endophytic fungi Eef2, Eef-7, Eef-13 and Eef-14 showed inhibitory activities against five tested bacteria, while Eef-3, Eef- 5 and Eef- 15 showed weak inhibition and displayed antibacterial activities against four tested bacteria.

Table 1 Identification of endophytic fungi isolated from Eucalyptus exserta

\begin{tabular}{|c|c|c|c|c|c|}
\hline $\begin{array}{l}\text { Fungal } \\
\text { isolate }\end{array}$ & CF (\%) & $\begin{array}{l}\text { Accession } \\
\text { number }\end{array}$ & $\begin{array}{l}\text { Macro- and microscopic } \\
\text { identification }\end{array}$ & Closest raleted species & $\begin{array}{l}\text { Similarity } \\
(\%)\end{array}$ \\
\hline Eef-1 & $12.50(10 / 80)$ & MK120854 & Phyllosticta sp. & EU167584.1 Phyllosticta elongata & 100 \\
\hline Eef-2 & $15.00(12 / 80)$ & MK120855 & Phyllosticta sp. & EU167584.1 Phyllosticta elongata & 99 \\
\hline Eef-3 & $5.00(4 / 80)$ & MK120856 & Penicillium sp. & $\begin{array}{l}\text { NR153252.1 Penicillium } \\
\text { citreosulfuratum }\end{array}$ & 99 \\
\hline Eef-4 & $2.50(2 / 80)$ & MK120857 & Eutypella sp. & KY962999.1 Eutypella scoparia & 98 \\
\hline Eef-5 & $6.25(5 / 80)$ & MK120858 & Purpureocillium sp. & KC157751.1 Purpureocillium lilacinum & 100 \\
\hline Eef-6 & $7.50(6 / 80)$ & MK120859 & Talaromyces sp. & MF093899.1 Talaromyces pinophilus & 99 \\
\hline Eef-7 & $2.50(2 / 80)$ & MK120860 & Lophiostoma sp. & HQ914838.1 Lophiostoma sp. & 98 \\
\hline Eef-8 & $2.50(2 / 80)$ & MK120861 & Cladosporium sp. & MF473305.1 Cladosporium tenuissimum & 100 \\
\hline Eef-9 & $5.25(5 / 80)$ & MK120862 & Pestalotiopsis sp. & LC184194.1 Pestalotiopsis sp. & 99 \\
\hline Eef-10 & $5.00(4 / 80)$ & MK120863 & Chaetomium sp. & KU504292.1 Chaetomium sp. & 100 \\
\hline Eef-11 & $7.50(6 / 80)$ & MK120864 & Fusarium sp. & LT841250.1 Fusarium proliferatum & 99 \\
\hline Eef-12 & $7.50(6 / 80)$ & MK120865 & Gongronella sp. & KM246758.1 Gongronella butleri & 99 \\
\hline Eef-13 & $3.75(3 / 80)$ & MK120866 & Scedosporium sp. & KC202949.1 Scedosporium boydii & 99 \\
\hline Eef-14 & $5.00(4 / 80)$ & MK120867 & Pseudallescheria sp. & KP132615.1 Pseudallescheria angusta & 99 \\
\hline Eef-15 & $7.50(6 / 80)$ & MK120868 & Eutypella sp. & KT868952.1 Eutypella sp. & 99 \\
\hline
\end{tabular}




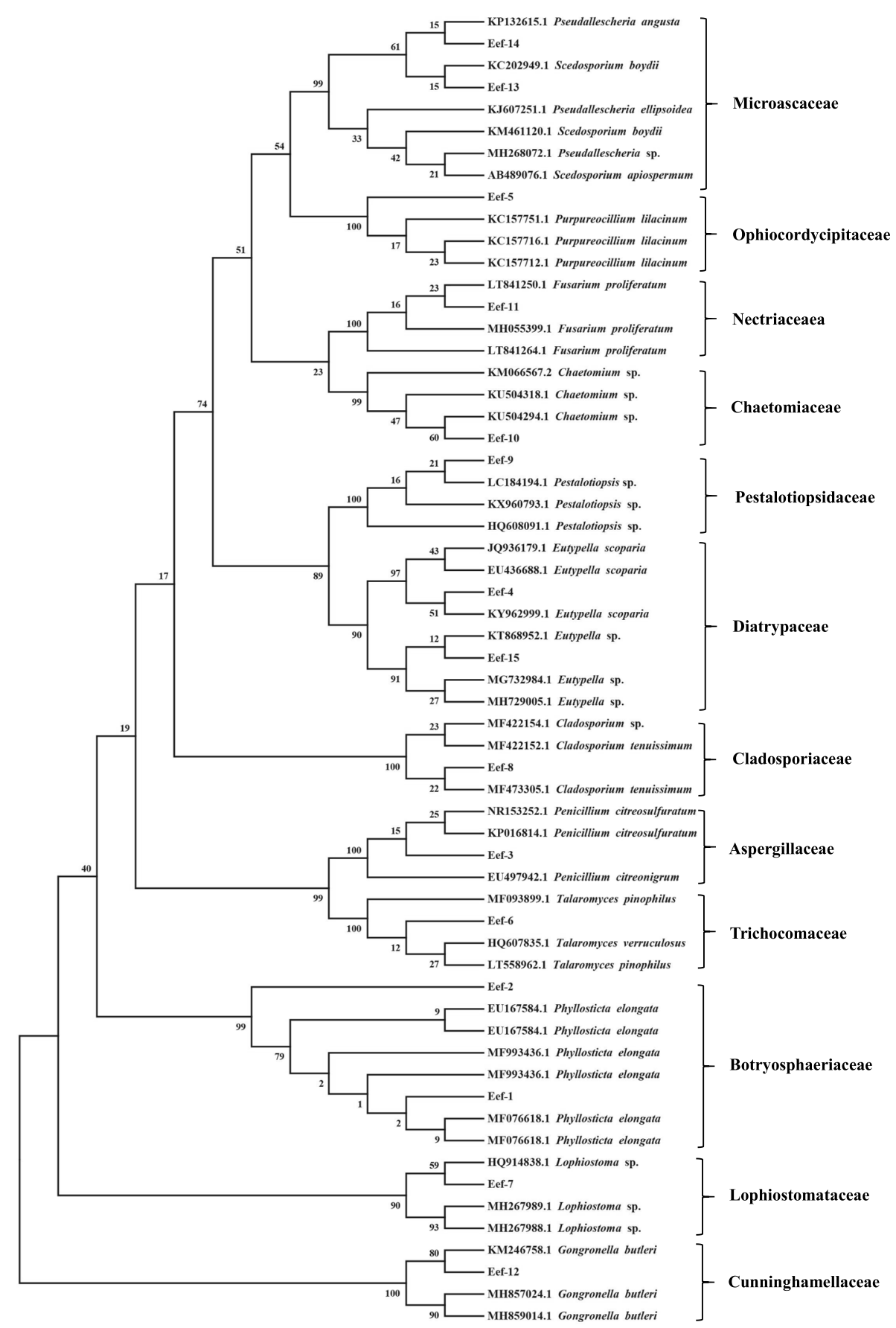

Fig. 2 Phylogenetic tree of endophytic fungi isolated from E. exserta based on the rDNA-ITS sequence. The tree was constructed with the maximum likelihood method in MEGA 6.0 using default parameters, and bootstrap values were calculated after 1,000 replications.

Interestingly, thirteen isolates showed antibacterial activity against $R$. solanacearum. Among these isolates, Eef- 9 and Eef-10 displayed the best inhibition, with inhibition spot diameters greater than $10 \mathrm{~mm}$ for both strains, while those of the remaining isolates were all less than $10 \mathrm{~mm}$. In addition, the endophytic fungus Eef-9 also displayed the best antibacterial activity against other tested bacteria, with inhibition spot diameters greater than $10 \mathrm{~mm}$ for all bacterial strains. The inhibition spot diameters of the endophytic fungus Eef-10 against Staphylococcus haemolyticus, X. vesicatoria and Pseudomonas lachrymans were more than $10 \mathrm{~mm}$. The endophytic fungus Eef-7 did not show inhibitory activity against $X$. vesicatoria and Escherichia coli, but the 
Table 2 Antibacterial activities of crude extracts of endophytic fungi isolated from E. exserta

\begin{tabular}{|c|c|c|c|c|c|c|c|}
\hline \multirow[t]{2}{*}{ Strains } & \multicolumn{7}{|c|}{$R_{\mathrm{f}}$ value (Inhibition spot diameter) } \\
\hline & R. solanacearum & S. aureus & B. subtilis & $\begin{array}{l}\text { S. } \\
\text { haemolyticus }\end{array}$ & $X$. vesicatoria & P. lachrymans & E. coli \\
\hline Eef-1 & $0.04-0.10^{+}$ & $0.00-0.28^{++}$ & $0.00-0.19^{++}$ & --- & $0.00-0.42^{+}$ & --- & 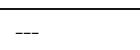 \\
\hline Eef-2 & $0.00-0.49^{++}$ & $0.00-0.38^{++}$ & $0.00-0.27^{++}$ & --- & $\begin{array}{l}0.00-0.38^{+} ; 0.48- \\
0.60^{++}\end{array}$ & $\begin{array}{l}0.02-0.03^{+} ; 0.08-0.11^{+} ; \\
0.24-0.27^{+} ; 0.37-0.44^{+}\end{array}$ & --- \\
\hline Eef-3 & $\begin{array}{l}0.00-0.38^{+} ; 0.47- \\
0.52^{+}\end{array}$ & $0.15-0.75^{++}$ & --- & --- & $0.00-0.70^{++}$ & --- & $0.52-0.55^{+}$ \\
\hline Eef-4 & $0.34-0.52^{++}$ & $\begin{array}{l}0.00-0.09^{+} ; 0.12- \\
0.97^{++}\end{array}$ & $\begin{array}{l}0.03-0.06^{+} ; 0.16- \\
0.26^{+} ; 0.32-0.57^{++}\end{array}$ & $\begin{array}{l}0.11-0.22^{+} \\
0.42-0.83^{++}\end{array}$ & --- & $0.06-0.43^{+} ; 0.55-0.63^{++}$ & $\begin{array}{l}0.00-0.11^{+} \\
0.25-0.35^{++}\end{array}$ \\
\hline Eef-5 & $\begin{array}{l}0.00-0.27^{+} ; 0.32- \\
0.37^{+} ; 0.52-0.71^{+}\end{array}$ & $0.00-0.62^{+}$ & $0.00-0.73^{++}$ & --- & --- & $0.19-0.37^{+} ; 0.60-0.70^{+}$ & -- \\
\hline Eef-6 & $0.00-0.66^{++}$ & $0.00-0.22^{++}$ & $0.00-0.22^{++}$ & $0.14-0.17^{+}$ & $\begin{array}{l}0.00-0.34^{++} ; 0.35- \\
0.42^{++}\end{array}$ & $0.17-0.30^{+}$ & $\begin{array}{l}0.20-0.34^{+} \\
0.55-0.73^{+}\end{array}$ \\
\hline Eef-7 & $0.03-0.17^{++}$ & $0.03-0.86^{++}$ & $\begin{array}{l}0.03-0.19^{++} ; 0.28- \\
0.48^{++} ; 0.49- \\
0.93^{+++}\end{array}$ & $\begin{array}{l}0.17-0.29^{++} \\
0.49-0.95^{+++}\end{array}$ & --- & $0.00-0.82^{++}$ & --- \\
\hline Eef-8 & $\begin{array}{l}0.12-0.18^{+} ; 0.38- \\
0.62^{+} ; 0.78-0.86^{++}\end{array}$ & $0.15-0.75^{++}$ & $0.19-0.48^{++}$ & --- & -- & $0.03-0.29^{+} ; 0.68-0.72^{+}$ & --- \\
\hline Eef-9 & $\begin{array}{l}0.00-0.31^{+} ; 0.41- \\
0.49^{+++}\end{array}$ & $0.00-0.23^{+++}$ & $0.00-0.28^{+++}$ & $\begin{array}{l}0.0-0.20^{++} \\
0.67-0.70^{+++}\end{array}$ & $0.00-0.29^{+++}$ & $\begin{array}{l}0.00-0.24^{+} ; 0.32-0.49^{++} \\
0.57-0.65^{+++}\end{array}$ & $\begin{array}{l}0.00- \\
0.18^{+++}\end{array}$ \\
\hline Eef-10 & $0.00-0.78^{+++}$ & $0.05-0.25^{++}$ & $\begin{array}{l}0.06-0.17^{+} ; 0.23- \\
0.36^{++}\end{array}$ & $0.0-0.92^{+++}$ & $0.00-0.82^{+++}$ & $0.00-0.81^{+++}$ & $\begin{array}{l}0.00-0.72^{+} \\
0.82-0.91^{++}\end{array}$ \\
\hline Eef-11 & $0.00-0.07^{+}$ & $\begin{array}{l}0.00-0.17^{++} ; 0.22- \\
0.27^{+} ; 0.37-0.42^{++}\end{array}$ & $\begin{array}{l}0.00-0.08^{+} ; 0.13- \\
0.17^{+} ; 0.35-0.48^{+}\end{array}$ & $0.00-0.27^{++}$ & $\begin{array}{l}0.00-0.17^{++} ; 0.22- \\
0.28^{+} ; 0.33-0.43^{++} ;\end{array}$ & $0.20-0.25^{+} ; 0.35-0.4^{+}$ & $0.10-0.18^{+}$ \\
\hline Eef-12 & $0.00-0.05^{+}$ & $\begin{array}{l}0.00-0.17^{++} ; 0.20- \\
0.23^{+}\end{array}$ & $\begin{array}{l}0.00-0.18^{++} ; 0.18- \\
0.25^{+}\end{array}$ & $0.00-0.5^{++}$ & $0.00-0.4^{++}$ & $0.00-0.08^{++}$ & $0.00-0.20^{++}$ \\
\hline Eef-13 & --- & $\begin{array}{l}0.00-0.05^{+} ; 0.38- \\
0.47^{+}\end{array}$ & $\begin{array}{l}0.13-0.32^{+} ; 0.38- \\
0.52^{++}\end{array}$ & $0.00-0.08^{+}$ & $0.00-0.38^{++}$ & $0.00-0.2^{++} ; 0.30-0.45^{++}$ & --- \\
\hline Eef-14 & --- & $0.00-0.22^{++}$ & $0.00-0.22^{++}$ & --- & $\begin{array}{l}0.00-0.34^{+} ; 0.35- \\
0.42^{++}\end{array}$ & $0.17-0.30^{+}$ & $\begin{array}{l}0.20-0.34^{+} ; \\
0.55-0.73^{+}\end{array}$ \\
\hline Eef-15 & $\begin{array}{l}0.00-0.38^{+} ; 0.47- \\
0.52^{+}\end{array}$ & $0.15-0.75^{++}$ & --- & --- & $0.00-0.70^{++}$ & --- & $0.52-0.55^{+}$ \\
\hline $\begin{array}{l}\text { Streptomycin } \\
\text { sulfate }\end{array}$ & ++ & ++ & +++ & ++ & ++ & +++ & ++ \\
\hline
\end{tabular}

---: Inhibition spot was not observed; +: Maximum inhibition spot diameter $\mathrm{d}<5 \mathrm{~mm}$; ++: Maximum inhibition spot diameter $5 \mathrm{~mm} \leq \mathrm{d}<10 \mathrm{~mm}$;++: Maximum inhibition spot diameter $\mathrm{d} \geq 10 \mathrm{~mm}$; The positive control streptomycin sulfate was only sampled on TLC plate.

inhibition spot diameters against Bacillus subtilis and $S$. haemolyticus were more than $10 \mathrm{~mm}$. In addition, although Eef-6, Eef-11 and Eef-12 inhibited all tested bacteria, the inhibition spot diameters were less than 10 $\mathrm{mm}$.

The $R_{\mathrm{f}}$ value is primarily related to the polarity of the secondary metabolites produced by endophytic fungi, where larger $R_{\mathrm{f}}$ values indicate lower polarity. In addition, a range of observed $R_{\mathrm{f}}$ values is related to the number and antibacterial activity of the secondary metabolites, with a larger range of the $R_{\mathrm{f}}$ values indicating that more antibacterial compounds have stronger antibacterial activities. The results showed that Eef-9, Eef-10 and Eef-7 displayed strong antibacterial activities and had the ability to produce valuable compounds. Therefore, this three endophytic fungi could be selected for further analysis and used as candidate strains for the further isolation and identification of active components.

\section{Purification and structure elucidation}

Eef-7 was selected for large-scale fermentation using sterilized rice medium. The solid fermentation product of the Eef- 7 was extracted with methanol $(\mathrm{MeOH})$, and the resulting extracts were partitioned into petroleum ether (PE)- and EtOAc-soluble fractions. The PE and EtOAc fractions were further purified by conventional chromatographic techniques, and three known compounds, scorpinone (1), 5-deoxybostrycoidin (2) and 4methyl-5,6-dihydro-2 $H$-pyran-2-one (3), were structurally characterized (Fig. 3).

The chemical structures of compounds 1-2 were elucidated through HR-ESI-MS and 1D and 2D NMR experiments (COSY, HSQC and HMBC), and compound 3 
<smiles>COc1cc(OC)c2c(c1)C(=O)c1cc(C)ncc1C2=O</smiles><smiles>COc1cc(O)c2c(c1)C(=O)c1cc(C)ncc1C2=O</smiles><smiles>CC1=CC(=O)OCC1</smiles>

Fig. 3 Chemical structures of scorpinone (1), 5-deoxybostrycoidin (2) and 4-methyl-5,6-dihydro-2 H-pyran-2-one (3)

was elucidated according to the ${ }^{1} \mathrm{H}$ NMR and ${ }^{13} \mathrm{C}$ NMR data and compared with the literature (Figs. S1, S2, S3, S4, S5, S6, S7, S8, S9, S10, S11, S12, S13, S14).

Scorpinone (1): yellow crystal; HR-ESI-MS m/z 284.092445 $[\mathrm{M}+\mathrm{H}]^{+}$(calcd. for $\mathrm{C}_{16} \mathrm{H}_{14} \mathrm{NO}_{4}, 284.09228$ ), $306.074175[\mathrm{M}+\mathrm{Na}]^{+}$(calcd. for $\mathrm{C}_{16} \mathrm{H}_{13} \mathrm{NNaO}_{4}$, 306.07423); ${ }^{1}$ H NMR and ${ }^{13} \mathrm{C}$ NMR see Table 3; and the key HMBC correlations see Fig. 4. The structure of compound $\mathbf{1}$ was confirmed by comparison with literature data [26].

Table $3^{13}$ C-NMR and ${ }^{1}$ H-NMR data for compounds $1-2$ (in $\left(\mathrm{CDCl}_{3}\right)$

\begin{tabular}{|c|c|c|c|c|}
\hline \multirow[t]{2}{*}{ Position } & \multicolumn{2}{|c|}{$1(\delta$ in ppm, $J$ in $\mathrm{Hz})$} & \multicolumn{2}{|c|}{$2(\delta$ in ppm, $J$ in $\mathrm{Hz})$} \\
\hline & $\overline{\delta_{\mathrm{c}}}$ & $\delta_{\mathrm{H}}$ & $\overline{\delta_{c}}$ & $\delta_{\mathrm{H}}$ \\
\hline 1 & 149.89 & $9.40(\mathrm{~s})$ & 149.20 & $9.41(\mathrm{~s})$ \\
\hline 3 & 162.94 & - & 165.69 & - \\
\hline $3-\mathrm{CH}_{3}$ & 25.17 & $2.74(\mathrm{~s})$ & 25.43 & 2.77 (s) \\
\hline 4 & 117.57 & $7.80(\mathrm{~s})$ & 118.67 & $7.86(\mathrm{~s})$ \\
\hline 5 & 103.74 & $7.42(d, 2.4)$ & 107.53 & $7.34(d, 2.5)$ \\
\hline 6 & 164.26 & - & 166.01 & - \\
\hline 6- $\mathrm{OCH}_{3}$ & 56.49 & 4.01 (s) & 56.28 & $3.94(\mathrm{~s})$ \\
\hline 7 & 105.64 & $6.83(d, 2.4)$ & 108.34 & $6.74(d, 2.5)$ \\
\hline 8 & 165.14 & - & 166.58 & - \\
\hline $8-\mathrm{OH}$ & - & - & - & $12.76(\mathrm{~s})$ \\
\hline $8-\mathrm{OCH}_{3}$ & 56.75 & $3.99(\mathrm{~s})$ & - & - \\
\hline 9 & 180.61 & - & 182.42 & - \\
\hline 10 & 183.64 & - & 186.31 & - \\
\hline 11 & 137.16 & - & 138.74 & - \\
\hline 12 & 115.87 & - & 110.56 & - \\
\hline 13 & 137.70 & -- & 124.28 & - \\
\hline 14 & 125.62 & & 134.61 & - \\
\hline
\end{tabular}

5-Deoxybostrycoidin (2): light yellow power; HR-ESIMS m/z $268.061917[\mathrm{M}-\mathrm{H}]^{-}$(calcd. for $\mathrm{C}_{15} \mathrm{H}_{10} \mathrm{NO}_{4}$, 268.06098); ${ }^{1} \mathrm{H}$ NMR and ${ }^{13} \mathrm{C}$ NMR see Table 3; and the key HMBC correlations see Fig. 4. The data were consistent with the literature [27].

4-Methyl-5,6-dihydro-2 $H$-pyran-2-one (3): colorless oil; ${ }^{1} \mathrm{H}$ NMR (acetone- $\left.d_{6}, 600 \mathrm{MHz}\right) \delta_{\mathrm{H}} 5.71(1 \mathrm{H}, \mathrm{s}, \mathrm{H}-$ 3), $4.32(2 \mathrm{H}, \mathrm{t}, J=6.2 \mathrm{~Hz}, \mathrm{H}-6), 2.42(2 \mathrm{H}, \mathrm{t}, J=6.2 \mathrm{~Hz}$, $\mathrm{H}-5), 2.01(3 \mathrm{H}, \mathrm{s}, \mathrm{H}-7)$; and ${ }^{13} \mathrm{C}$ NMR (acetone- $d_{6}$, $151 \mathrm{MHz}) \delta_{\mathrm{C}} 164.55(\mathrm{C}-2), 159.51$ (C-4), 116.95 (C-3), 66.64 (C-6), 29.75 (C-5), 22.87 (C-7). The ${ }^{1}$ H NMR and ${ }^{13} \mathrm{C}$ NMR data were consistent with the literature [28].

\section{Antibacterial activities of pure compounds against $R$. solanacearum}

Compounds 1 and 2 were further evaluated for their antibacterial activities against $R$. solanacearum. Both compounds 1 and 2 showed weak antibacterial effects against the tested bacterium (Table 4). The inhibition zone diameter of streptomycin sulfate was $13.03 \pm 0.43$ $\mathrm{mm}$ at an additive amount of $6.25 \mu \mathrm{g}$.

\section{Discussion}

Endophytic fungi that colonize plant tissues cause no symptoms of tissue damage and play important roles in the ecosystem function of their hosts [29, 30]. Endophytic fungi have formed a symbiotic relationship with their host plants in the long-term process of coevolution, providing nutrients that promote the defense mechanisms of plants and enhancing their ability to resist adverse conditions, diseases, and insect pests [31, 32]. Endophytic fungi are widely present in all parts of plants, but the species and quantity of endophytic fungi vary greatly in different plants and in different parts of the same plant [1]. Endophytic fungal species are also related to the growing age, season and different tissues 


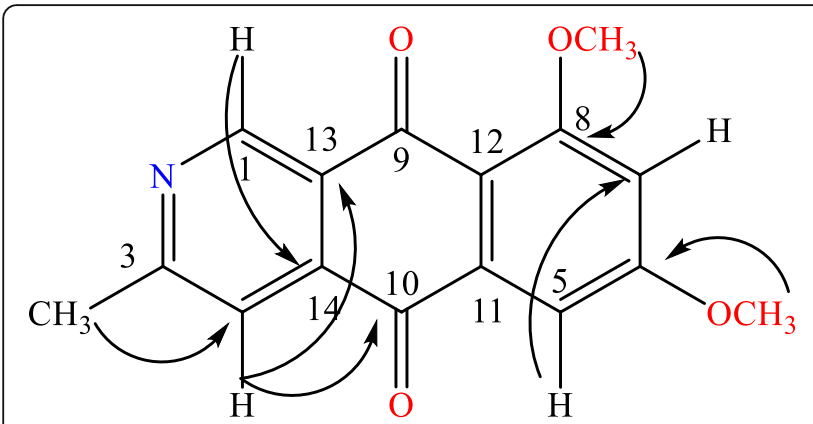

1

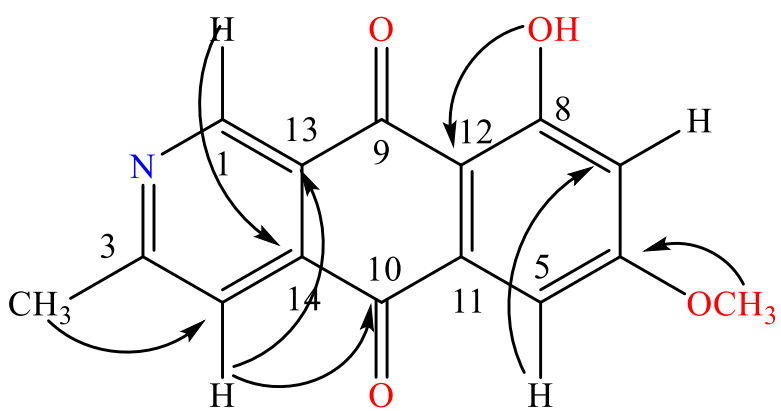

2

Fig. 4 Key HMBC (H-C) correlations of scorpinone (1) and 5-deoxybostrycoidin (2)

and organs of the host plant [33]. In the present study, only 15 different endophytic fungi were isolated and identified from the branches and fruits of E. exserta, a result that may be related to the host plants and their living environment. Most endophytic fungi cannot be cultured on artificial medium, and as potato dextrose agar (PDA) is not necessarily an optimal medium, the 15 endophytic fungi isolated in this study represent only some of the endophytic fungi of E. exserta. In subsequent studies, different media and high-throughput sequencing can be used to isolate as many endophytic fungi as possible, and the distribution and growth of endophytic fungi in different media can be compared.

Endophytic fungi play a crucial role in the agricultural and forestry sectors owing to their ability to improve crop yield, enhance plant disease resistance and reduce the use of chemical pesticides, which is beneficial for the protection of the environment and human health [34]. Some bioactive secondary metabolites isolated from endophytic fungi have shown significant economic value and application prospects in the biological control of plant diseases and in drug research and development [35]. Endophytic fungi are a reservoir of antibacterial agents [24]. For example, the endophytic fungus Nigrospora sphaerica was isolated from the leaves of Indigofera suffruticosa, which has been shown to produce bioactive agents with pharmaceutical potential [22]. Nine new Spirobisnaphthalenes were isolated from the endophytic fungi Berkleasmium sp. associated with Dioscorea zingiberensis, and all isolated compounds have been evaluated for their antibacterial activities against six different bacteria [36]. The isolation and

Table 4 Antibacterial activities of compounds 1 and 2 against $R$. solanacearum

\begin{tabular}{llllll}
\hline Samples & \multicolumn{5}{l}{ Inhibition zone diameter $(\mathbf{m m})$} \\
\cline { 2 - 6 } & $\mathbf{4} \boldsymbol{\mu g}$ & $\mathbf{8} \boldsymbol{\mu g}$ & $\mathbf{1 6} \boldsymbol{\mu g}$ & $\mathbf{3 2} \boldsymbol{\mu g}$ & $\mathbf{6 4} \mathbf{\mu g}$ \\
\hline 1 & $6.43 \pm 0.69$ & $8.71 \pm 0.53$ & $8.98 \pm 0.71$ & $9.33 \pm 0.63$ & $9.86 \pm 0.75$ \\
2 & $7.19 \pm 0.22$ & $8.04 \pm 0.39$ & $8.71 \pm 0.30$ & $9.12 \pm 0.22$ & $9.58 \pm 0.60$ \\
\hline
\end{tabular}

identification of endophytic mycobiota is necessary since the medicinal properties of a plant can result from the ability of its endophytic microorganisms to produce biologically active secondary metabolites [37, 38]. In the present study, the endophytic fungi Eef-9 (Pestalotiopsis sp., MK120862), Eef-10 (Chaetomium sp., MK120863) and Eef-7 (Lophiostoma sp., MK120860) displayed potent antibacterial activities and had the ability to produce valuable compounds that require further analysis. At present, strains of the same genus as Eef-9 (Pestalotiopsis sp., MK120862), Eef-10 (Chaetomium sp., MK120863) and Eef-7 (Lophiostoma sp., MK120860) have been reported as endophytic fungi in a variety of plants. Pestalotiopisorin B, a new isocoumarin derivative isolated from the mangrove endophytic fungus Pestalotiopsis sp. HHL101, exhibited modest antibacterial activity against Escherichia coli and Pseudomonas aeruginosa [39]. Two new butenolides (pestalolides B and C) and two new diphenyl ethers (pestalotethers $\mathrm{E}$ and $\mathrm{F}$ ) together with seven known compounds were isolated from the endophytic fungus Pestalotiopsis sp. living in the leaves of tea trees and displayed cytotoxic activities against four different human tumor cell lines [40]. In our previous study, seven depsidones, including four new depsidones mollicellins $\mathrm{O}-\mathrm{R}$, were isolated from cultures of the endophytic fungus Chaetomium sp. Eef- 10 . Mollicellin $\mathrm{H}$ displayed the best antibacterial activity against S. aureus ATCC29213 and S. aureus N50 (MRSA), and mollicellin $G$ was active against two human cancer cell lines (HepG2 and HeLa). In addition, mollicellin $\mathrm{O}$ showed antioxidant activity with an $\mathrm{IC}_{50}$ value of $71.92 \mu \mathrm{g} / \mathrm{mL}$ [7].

Although members of the genus Lophiostoma have been reported as endophytes or saprophytes from freshwater, terrestrial or marine environments, registered chemical investigations have primarily focused on marine-derived species [29, 41, 42]. Lophiostomin A-D, new 3,4-dihydroisocoumarin congeners, were isolated from the endophytic fungus Lophiostoma sp. of Siraitia grosvenorii, and lophiostomin A and B displayed 
moderate inhibitory activities against the germination of Magnaporthe oryzae spores [29]. In the present study, three known compounds were isolated from the endophytic fungus Lophiostoma sp. Eef-7, and compounds 1 and 2 were both 2-azaanthraquinones, a class of polyketide-derived heterocycles primarily produced in nature by fungi or lichens that display phytotoxic effects and activity against various microorganisms [43, 44]. Scorpinone (1) has been isolated from a newly described fungus, Amorosia littoralis [26], and the biogenetic origin of the carbon atoms was assessed through isotopic enrichment studies using $\left[2-{ }^{13} \mathrm{C}\right]$-acetate and $\left[1,2-{ }^{13} \mathrm{C}\right]$ acetate. The labeling results revealed that a heptaketide precursor is involved in the biosynthesis of scorpinone (1), which as has also been observed for the structurally related naphthoquinone dihydrofusarubin [44]. Compound 2 was reported as a new melanin, a secondary metabolite made up of complex heterogeneous polymers of phenolic and/or indolic monomers [45]. 5-Deoxybostrycoidin (2) is located within the periderm of perithecia of the Fusarium graminearum group and synthesized from the reaction of anhydrofusarubin derivatives and ammonia [46]. Several Fusarium species, including F. graminearum, F. verticillioides, and F. fujikuroi $[46,47]$, produce blackish perithecial pigments. The fungus $\mathrm{Nec}$ tria haematococca has also been reported to produce compound 2 [27], a pigment that is important for UV or desiccation protection during the differentiation of perithecia and ascospores [48-50]. Compound 2 also displayed significant cytotoxicity against the MDA-MB-435 and NCI-H460 cell lines, with $\mathrm{IC}_{50}$ values of 5.32 and $6.57 \mu \mathrm{M}$, respectively [51].

\section{Conclusions}

In the present study, endophytic fungi were reported from the Chinese afforestation tree species $E$. exserta for the first time and exhibited antibacterial activity based on TLC bioautography assays. Fifteen endophytic fungi were identified from E. exserta, and Eef-9, Eef-10 and Eef-7 displayed potent antibacterial activities. All strains showed antibacterial activity, including four with widespectrum activity. The percentage of endophytic fungi isolated from fruits and branches of E. exserta revealed the enormous capacity for the bioactive compounds production with antimicrobial potential. The three most active strains (Pestalotiopsis sp. Eef-9, Chaetomium sp. Eef-10 and Lophiostoma sp. Eef-7) will be studied for taxonomy and isolation of antimicrobial compounds by using liquid and semisolid fermentation assays. In summary, endophytic fungi from $E$. exserta contribute to antimicrobial activity of the host plant and should be investigated as alternative sources of antimicrobial agents in the future.

\section{Materials and methods}

\section{Plant material}

Healthy branches and fruits of Eucalyptus exserta F. V. Muell. were collected in June 2014 from the campus of South China Agricultural University (SCAU, 2310' N, $113^{\circ} 21^{\prime} \mathrm{E}$ at an altitude of $23.6 \mathrm{~m}$ ), Guangzhou, Guangdong Province, China. Guangzhou is located on the subtropical coast, and the Tropic of Cancer runs through the central and southern parts of the city. This region has a maritime subtropical monsoon climate, characterized by warm and rainy conditions, sufficient light and heat, long summers and short frost periods. The annual average temperature ranges from 20 to $22{ }^{\circ} \mathrm{C}$, and the average annual rainfall ranges from 1,623.6-1,899.8 $\mathrm{mm}$. The taxonomic identification of the plant materials was performed by Dr. Mingxuan Zheng of College of Forestry and Landscape Architecture (SCAU), where the voucher specimen (SCAULPMH-140,605) of the plant was deposited.

\section{Isolation and cultivation of endophytic fungi}

The isolation of endophytic fungi was performed by following the process described in our previous report with some modifications [20]. Briefly, first, the healthy branches and fruits of $E$. exserta collected from eight different trees were thoroughly washed under running tap water. Then, the samples were surface sterilized by dipping them in $75 \%$ ethanol for $30 \mathrm{~s}$, followed by immersion in $0.2 \%$ mercuric chloride for $20 \mathrm{~min}$. The samples were then rinsed in sterile distilled water three times ( 5 min each time) and finally dried on sterile filter paper. The epidermis of each branch explant was removed with a sterile scalpel. The sterilization process was confirmed by placing the sterile epidermal tissues on PDA (200 g/L potato, $20 \mathrm{~g} / \mathrm{L}$ dextrose, and $20 \mathrm{~g} / \mathrm{L}$ agar) Petri dishes. After sterilization, each explant (without epidermis) was cut into $5 \times 5 \times 5 \mathrm{~mm}$ cubes, which were individually placed on PDA plates supplemented with streptomycin sulfate $(500 \mathrm{mg} / \mathrm{L})$ to suppress bacterial growth. After the plates were incubated in the dark at $28{ }^{\circ} \mathrm{C}$ for $7-30$ days, the number of fungi was counted, and each fungal colony was isolated and subcultured to obtain a pure culture. The CF of each endophyte was also calculated [52]. CF $(\%)=\left(N_{C O L} / N_{t}\right) \times 100$, where $N_{C O L}$ is the number of cubes colonized by each fungus and $N_{t}$ is the total number of cubes. All the isolated fungi were deposited at the College of Forestry and Landscape Architecture, South China Agricultural University.

\section{General experimental procedures}

The morphological characteristics of the endophytic fungi isolated from $E$. exserta were observed using a CX31 Digital Fluorescence Microscope (Mshot, 
Guangzhou, China). High-resolution electrospray ionization mass spectrometry (HR-ESI-MS) was carried out on a Q-TOF mass spectrometer from Bruker maXis with an ESI interface (Bruker, Fremont, CA, USA). Nuclear magnetic resonance (NMR; ${ }^{1} \mathrm{H}$ and ${ }^{13} \mathrm{C}$ ) spectra were recorded on a Bruker Avance-600 NMR spectrometer $\left({ }^{1} \mathrm{H}\right.$ at $600 \mathrm{MHz}$ and ${ }^{13} \mathrm{C}$ at $151 \mathrm{MHz}$ ) (Bruker, Fremont, CA, USA). Semi-preparative HPLC separation was performed on a Lumtech instrument equipped with an HPLC K-501 pump and a K-2501 UV detector using a Wondasil 38020-41 $\mathrm{C}_{18}$ column $(250 \mathrm{~mm} \times 21.2 \mathrm{~mm}$, $5 \mu \mathrm{m}$, Welch Materials Inc.). Water used for experiments was purified with an ultrapure water machine (Exceed-Cb-10, Aike, Chengdu, China). $\mathrm{MeOH}$ was of HPLC grade, and all the other reagents were of analytical grade. All solvents used for HPLC were filtered through a $0.45 \mu \mathrm{m}$ nylon membrane before use. Silica gel (60-100, 100-200 and 200-300 mesh, Qingdao Marine Chemical Inc.) and Sephadex LH-20 (GE Healthcare) were used for separation and isolation. Precoated silica gel GF-254 plates (Qingdao Marine Chemical Inc.) were used for analytical TLC. Spots were visualized under UV light (254 or $356 \mathrm{~nm})$.

\section{Morphological characterization}

The morphological characteristics, including colony diameter, texture, color, dimensions and morphology of hyphae and conidia of the fungal isolates, were observed and described according to previously described methods [52].

\section{DNA extraction, ITS-rDNA amplification and sequence analysis}

Total genomic DNA of the fungal isolates was prepared using a modified protocol for the rapid preparation of DNA from filamentous fungi [34]. The primers ITS 4 (5'-TCCTCCGCTTATTGATATGC-3') and ITS 5 (5'GGAAGTAAAAGTCGTAACAAGG-3') as well as ITSrDNA amplification conditions were described in our previous report. The resulting ITS-rDNA sequences were edited using the BLASTn program against the NCBI database and were submitted to GenBank to obtain accession numbers.

\section{Fungal material and preparation EtOAc extracts}

The purified fungal isolates were cultured on PDA Petri dishes at $25{ }^{\circ} \mathrm{C}$ for 10 days. Then, agar plugs harboring mycelia were obtained using a cork borer, and 2-3 plugs were inoculated into $50-\mathrm{mL}$ Erlenmeyer flasks containing $20 \mathrm{~mL}$ of potato dextrose broth (PDB). All flasks were incubated on a rotary shaker at $150 \mathrm{rpm}$ and $28{ }^{\circ} \mathrm{C}$ for 7 days to obtain seed cultures. Subsequently, the seed cultures were transferred into 500-mL Erlenmeyer flasks containing $100 \mathrm{~g}$ of rice medium under static conditions and incubated at $28{ }^{\circ} \mathrm{C}$ for 60 days. The preparation of the rice medium was performed according to the methodology described in our previous report [1].

After incubation, $\mathrm{MeOH}(3 \times 300 \mathrm{~mL})$ was added to each Erlenmeyer flask, followed by maceration and shaking at $100 \mathrm{rpm}$ at room temperature for $72 \mathrm{~h}$, after which each sample was subjected to vacuum filtration. Then, the filtrates were concentrated on a rotary evaporator under reduced pressure to obtain methanolic extracts. The methanolic extracts were then extracted with EtOAc $(3 \times 300 \mathrm{~mL})$ by partitioning in a separatory funnel (solvent-solvent extraction). Finally, the culture filtrates were concentrated on a rotary evaporator under reduced pressure to obtain EtOAc extracts.

\section{Antibacterial activity of EtOAc crude extracts}

A TLC-3-(4,5-dimethylthiazol-2-yl)-2,5-diphenyl tetrazolium bromide (MTT)-bioautography assay of the samples was performed according to a previously described method [53]. Three gram-positive (Staphylococcus aureus ATCC 6538, Staphylococcus haemolyticus ATCC 29, 970, and Bacillus subtilis ATCC 11,562) and four gramnegative (Escherichia coli ATCC 25,922, Pseudomonas lachrymans ATCC11921, Xanthomonas vesicatoria ATCC 11,633, and Ralstonia solanacearum ATCC 11, 696) bacterial strains were selected for the antibacterial assay. Each EtOAc extract $(20 \mathrm{mg})$ was dissolved in 1 $\mathrm{mL}$ of methanol with ultrasonic assistance, after which 5 $\mu \mathrm{L}$ of the sample solution was sampled onto a TLC plate, and TLC was performed using a chloroform $\left(\mathrm{CHCl}_{3}\right)-\mathrm{MeOH}(15: 1, \mathrm{v} / \mathrm{v})$ solvent system. After completion of TLC, $5 \mu \mathrm{L}$ of streptomycin sulfate $\left(\mathrm{CK}^{+}\right)$solution $(0.2 \mathrm{mg} / \mathrm{mL})$ was sampled onto the lower right side of the TLC plate. Then, the TLC plate was placed on an ultraclean table and ventilated to remove the solvent. The TLC plate was then covered with a bacterial test suspension and incubated at $28{ }^{\circ} \mathrm{C}$ for $12 \mathrm{~h}$, after which it was sprayed with the colorimetric reagent MTT $(0.5 \mathrm{mg} / \mathrm{mL})$ and incubated for another $2 \mathrm{~h}$. Antibacterial activity was determined by the formation of welldefined inhibition zones made visible by spraying with MTT, which is converted to a formazan dye by living microorganisms. Antibacterial activity was detected as white inhibition zones against a purple background, and the diameter of each antibacterial area was measured. All tests were performed in triplicate.

\section{Fermentation and extraction of endophytic fungus Eef-7}

The fermentation and extraction of secondary metabolites produced by the endophytic fungus Eef- 7 were performed according to a previously described method [7]. The endophytic fungus Eef-7 was cultured on PDA medium at $28{ }^{\circ} \mathrm{C}$ for 14 days. Then, three agar plugs $(0.5 \times 0.5 \mathrm{~cm})$ were inoculated into a $500-\mathrm{mL}$ Erlenmeyer 
flask containing $200 \mathrm{~mL}$ of PDB (potato $200 \mathrm{~g} / \mathrm{L}$ and dextrose $20 \mathrm{~g} / \mathrm{L}$ ) medium and incubated on a rotary shaker at $150 \mathrm{rpm}$ and $28{ }^{\circ} \mathrm{C}$ for 7 days. Subsequently, the obtained seed cultures were added to sterilized rice medium ( $3 \mathrm{~kg}$ in total) and incubated at $28{ }^{\circ} \mathrm{C}$ for 60 days. The fermented rice material was then extracted with $\mathrm{MeOH} 3$ times, after which the $\mathrm{MeOH}$ extracts were dissolved in $1 \mathrm{~L}$ of sterilized distilled water and successively partitioned with $\mathrm{PE}$ and EtOAc at room temperature. The pooled PE and EtOAc extracts were dried under vacuum to obtain crude extracts of $20.03 \mathrm{~g}$ (PE) and $26.15 \mathrm{~g}$ (EtOAc).

\section{Isolation of secondary metabolites produced by endophytic fungus Eef-7}

The PE extract (20.03 g) was subjected to column chromatography over a silica gel (200 - 300 mesh) eluted with a gradient of PE-acetone (100:0-0:100) to afford eleven fractions. Fraction 9 (256 mg) was chromatographed over Sephadex LH-20 (eluted with $\mathrm{CHCl}_{3}-\mathrm{MeOH}, 1: 1$ ) to obtain six subfractions. Subfraction $3(164.2 \mathrm{mg})$ was further purified by semi-preparative HPLC elution with a gradient of $\mathrm{MeOH}-\mathrm{H}_{2} \mathrm{O}$ (0-5 min, $\mathrm{MeOH} 40 \%$; 5-45 min, $\mathrm{MeOH}$ 40-100\%; flow rate $4 \mathrm{~mL} / \mathrm{min}$ with an isocratic $0.01 \%$ TFA modifier) to obtain compound 2. Fraction 11 (122 mg) was also chromatographed over Sephadex LH20 (eluted with $\mathrm{CHCl}_{3}-\mathrm{MeOH}, 1: 1$ ) to obtain four subfractions. Subfraction $2(16 \mathrm{mg})$ was further purified by semipreparative HPLC eluting with $\mathrm{MeOH}-\mathrm{H}_{2} \mathrm{O}$ (70:30, flow rate $4 \mathrm{~mL} / \mathrm{min}$ with an isocratic $0.01 \%$ TFA modifier) to obtain compound 1.

The EtOAc extract $(26.15 \mathrm{~g})$ was subjected to column chromatography over silica gel (200-300 mesh) eluted with a gradient of PE-acetone (100:0-0:100) to obtain fourteen fractions. Fraction $5(140 \mathrm{mg})$ was chromatographed over Sephadex LH-20 (eluted with $\mathrm{CHCl}_{3}$ $\mathrm{MeOH}, 1: 1)$ to obtain six subfractions. Subfraction 2 (68 mg) was further purified by semi-preparative HPLC eluting with $\mathrm{MeOH}-\mathrm{H}_{2} \mathrm{O}$ (25:75, with an isocratic $0.01 \%$ TFA modifier, $4 \mathrm{~mL} / \mathrm{min}$ ) to afford compound 3. Fractions 6-8 (398 $\mathrm{mg})$ was also chromatographed over Sephadex LH-20 (eluted with $\mathrm{CHCl}_{3}-\mathrm{MeOH}, 1: 1$ ) to obtain five subfractions. Compound 1 (182.4 mg) was crystallized from subfractions $2-4$ and further purified by recrystallization.

\section{Antibacterial assay of pure compounds isolated from the endophytic fungus Eef-7}

$R$. solanacearum was used to assess the antibacterial activity of pure compounds. Streptomycin sulfate was used as a positive control. The inhibition zone diameters of the compounds and positive control were determined using the modified filter paper diffusion method as previously described [54].

\section{Supplementary Information}

The online version contains supplementary material available at https://doi. org/10.1186/s12866-021-02229-8.

\begin{abstract}
Additional file 1:Sup Fig. S1 HR-ESI-MS spectrum of scorpinone (1). Sup Fig. $\mathbf{S 2}{ }^{1}$ H NMR spectrum of scorpinone (1) $\left(\mathrm{CDCl}_{3}\right.$, $600 \mathrm{MHz})$. Sup Fig. $\mathbf{S 3}{ }^{13} \mathrm{C}$ NMR spectrum of scorpinone (1) $\left(\mathrm{CDCl}_{3}\right.$, $151 \mathrm{MHz})$. Sup Fig. S4 ${ }^{1}{ }^{1} \mathrm{H}$ COSY spectrum of scorpinone (1) $\left(\mathrm{CDCl}_{3}\right.$, $151 \mathrm{MHz})$. Sup Fig. S5 HSQC spectrum of scorpinone (1) $\left(\mathrm{CDCl}_{3}\right.$, $151 \mathrm{MHz})$. Sup Fig. S6 HMBC spectrum of scorpinone (1) $\left(\mathrm{CDCl}_{3}\right.$, $151 \mathrm{MHz}$ ). Sup Fig. S7 HR-ESI-MS spectrum of 5-deoxybostrycoidin (2). Sup Fig. S8 ${ }^{1}$ H NMR spectrum of 5-deoxybostrycoidin (2) $\left(\mathrm{CDCl}_{3}\right.$, $600 \mathrm{MHz}$ ). Sup Fig. S9 $^{13} \mathrm{C}$ NMR spectrum of 5-deoxybostrycoidin (2) $\left(\mathrm{CDCl}_{3}, 151 \mathrm{MHz}\right)$. Sup Fig. S10 ${ }^{1}{ }^{1} \mathrm{H}$ COSY spectrum of 5-

deoxybostrycoidin (2) $\left(\mathrm{CDCl}_{3}, 151 \mathrm{MHz}\right)$. Sup Fig. S11 HSQC spectrum of 5-deoxybostrycoidin (2) $\left(\mathrm{CDCl}_{3}, 151 \mathrm{MHz}\right)$. Sup Fig. S12 HMBC spectrum of 5-deoxybostrycoidin (2) $\left(\mathrm{CDCl}_{3}, 151 \mathrm{MHz}\right)$. Sup Fig. $\mathbf{S 1 3}{ }^{1} \mathrm{H}$ NMR spectrum of 4-methyl-5,6-dihydro-2-pyranone (3) (acetone- $d_{6}$, $600 \mathrm{MHz}$ ). Sup Fig. $\mathbf{S 1 4}{ }^{13} \mathrm{C}$ NMR spectrum of 4-methyl-5,6-dihydro-2pyranone (3) (acetone- $d_{6}, 151 \mathrm{MHz}$ ).
\end{abstract}

\section{Acknowledgements}

We thank Dr. Mingxuan Zheng from the College of Forestry and Landscape Architecture, South China Agricultural University, for the taxonomic identification of the plant materials.

\section{Authors' contributions}

Z.M., W.Z., Z.C. and T.S. performed the isolation, structure elucidation and recorded the spectra of the compounds. C.W., H.F. and T.S. performed the Isolation and identification of the endophytic fungi. Z.M., H.F., Y.P., H.S. and T.S. performed the Antimicrobial activity. P.D. and T.S. contributed in checking the data collection process. Z.M., C.W., Y.P. and T.S. contributed in preparing figures and tables. Z.M., P.D. and T.S. designed the research. All the authors contributed in writing, editing and revising the manuscript. The author(s) read and approved the final manuscript.

\section{Funding}

This research was co-financed by the National Natural Science Foundation of China (32071766, 31400544), the Natural Science Foundation of Guangdong Province (2019A1515011554), the Forestry Science and Technology Innovation Project of Guangdong Province (No. 2020KJCX004) and the Key Research and Development Projects of Guangdong Province (2020B020214001).

\section{Availability of data and materials}

The generated nucleotide sequence of the endophytic fungal isolates (isolation number Eef-1 Eef-15) can be accessed in GenBank under accession numbers MK120854 to MK120868(https://blast.ncbi.nlm.nih.gov/Blast.cgi). The datasets generated and/or analyzed during the current study are available from the corresponding author on reasonable request.

\section{Declarations}

\section{Ethics approval and consent to participate}

The healthy branches and fruits of Eucalyptus exserta F. V. Muell. were collected in June 2014 from the campus of South China Agricultural University (SCAU), Guangzhou, Guangdong Province, China. The taxonomic identification of the plant materials was performed by Dr. Mingxuan Zheng of College of Forestry and Landscape Architecture (SCAU), where the voucher specimen (SCAULPMH-140605) of the plant was deposited. All experiments were approved by the College of Forestry and Landscape Architecture (SCAU) and were strictly evaluated in accordance with the IUCN Policy Statement on Research Involving Species at Risk of Extinction and the Convention on the Trade in Endangered Species of Wild Fauna and Flora.

\section{Consent for publication}

Not Applicable.

\section{Competing interests}

The authors declare that they have no competing interests. 


\section{Author details}

${ }^{1}$ Guangdong Key Laboratory for Innovative Development and Utilization of Forest Plant Germplasm, College of Forestry and Landscape Architecture, South China Agricultural University, 510642, No. 483, Wushan Road, Tianhe District, Guangdong 510642 Guangzhou, China. ${ }^{2}$ Guangdong Province Key Laboratory of Microbial Signals and Disease Control, South China Agricultural University, 510642 Guangzhou, China. ${ }^{3}$ School of Pharmaceutical Sciences, Guangzhou University of Chinese Medicine, No. 232, Waihuandong Road, Panyu District, Guangdong 510006 Guangzhou, China.

\section{Received: 15 February 2021 Accepted: 12 May 2021} Published online: 27 May 2021

\section{References}

1. Shan TJ, Feng H, Xie Y, Shao C, Wang J, Mao ZL. Endophytic fungi isolated from Eucalyptus citriodora Hook. f. and antibacterial activity of crude extracts. Plant Prot. 2019;45: 149-155.

2. Hernandez-Romano J, Mastache-Estrada LA, Molina-Sanchez DA, SerranoPlancarte R, Pena-Barrera C, Chavez-Bejar MI, Romero-Martinez N, LeconaValera AN. Stability and inhibitory capacity of bacteriophage phi RSP, a potential agent for the biocontrol of Ralstonia solanacearum. Rev Fitotec Mex. 2019:42:13-20.

3. Spago FR, Mauro CSI, Oliveira AG, Beranger JPO, Cely MVT, Stanganelli MM, Simionato AS, San Martin JAB, Andrade CGTJ, Mello JCP, Andrade G. Pseudomonas aeruginosa produces secondary metabolites that have biological activity against plant pathogenic Xanthomonas species. Crop Prot. 2014:62:46-54

4. Long QS, Liu LW, Zhao YL, Wang PY, Chen B, Li Z, Yang S. Fabrication of furan-functionalized quinazoline hybrids: their antibacterial evaluation, quantitative proteomics, and induced phytopathogen morphological variation studies. J Agric Food Chem. 2019;67:11005-11017.

5. Aksoy DY, Unal S. New antimicrobial agents for the treatment of Grampositive bacterial infections. Clin Microbiol Infect. 2008;14:411-420.

6. Toghueo RMK. Endophytes from Gingko biloba: the current status. Phytochem Rev. 2020;19:743-759.

7. Ouyang JK, Mao ZL, Guo H, Xie YY, Cui ZH, Sun J, Wu HX, Wen XJ, Wang J, Shan TJ. Mollicellins O-R, four new depsidones isolated from the endophytic fungus Chaetomium sp. Eef-10. Molecules. 2018;23:3218-3229.

8. Ikram M, Ali N, Jan G, Hamayun M, Jan FG, Iabal A. Novel antimicrobial and antioxidative activity by endophytic Penicillium roqueforti and Trichoderma reesei isolated from Solanum surattense. Acta Physiol Plant. 2019;41:164.

9. Hamayun M, Khan N, Khan MN, Qadir M, Hussain A, labal A, Khan SA, Rehman KU, Lee IJ. Antimicrobial and plant growth-promoting activities of bacterial endophytes isolated from Calotropis procera (Ait.) WT Aiton. Biocell. 2021;45:363-369.

10. Sharma A, Malhotra B, Kharkwal H, Kulkarni GT, Kaushik N. Therapeutic agents from endophytes harbored in Asian medicinal plants. Phytochem Rev. 2020;19:691-720.

11. Nisa S, Khan N, Shah W, Sabir M, Khan W, Bibi Y, Jahangir M, Haq IU, Alam S, Qayyum A. Identification and bioactivities of two endophytic fungi Fusarium fujikuroi and Aspergillus tubingensis from foliar parts of Debregeasia salicifolia. Arab J Sci Eng. 2020:45:4477-4487.

12. Li YY, Tan XM, Wang YD, Yang J, Zhang YG, Sun BD, Gong T, Guo LP, Ding G. Bioactive seco-sativene sesquiterpenoids from an Artemisia desertorum endophytic fungus, Cochliobolus sativus. J Nat Prod. 2020;83:1488-1494.

13. Rakshith D, Gurudatt DM, Rao HCY, Mohana NC, Nuthan BR, Ramesha KP, Satish S. 2020. Bioactivity-guided isolation of antimicrobial metabolite from Xylaria sp. Process Biochem. 2020;92:378-385.

14. Santos TFB, Carvalho CS, de Almeida MA, Delforno TP, Duarte ICS. 2020 Endophytic fungi isolated from Brazilian medicinal plants as potential producers of antioxidants and their relations with anti-inflammatory activity. 3 Biotech. 2020;10: 223-231.

15. d'Errico G, Aloj V, Flematti GR, Sivasithamparam K, Worth CM, Lombardi N, Ritieni A, Marra R, Lorito M, Vinale F. Metabolites of a Drechslera sp. endophyte with potential as biocontrol and bioremediation agent. Nat Prod Res. 2020. doi: https://doi.org/10.1080/14786419.2020.1737058

16. Gupta S, Chaturvedi P, Kulkarni MG, Staden JV. A critical review on exploiting the pharmaceutical potential of plant endophytic fungi. Biotechnol Adv. 2020;39: 107462.

17. Newman DJ, Cragg GM. Natural products as sources of new drugs over the 30 years from 1981 to 2010. J Nat Prod. 2012;75:311-335.
18. U'ren, JM, Dalling JW, Gallery RE, Maddison DR, Davis EC, Gibson CM, Arnold AE. Diversity and evolutionary origins of fungi associated with seeds of a neotropical pioneer tree: a case study for analyzing fungal environmental samples. Mycol Res. 2009;113:432-449.

19. Petrini O, Sieber, TN, Toti L, Viret O. Ecology, metabolite production, and substrate utilization in endophytic fungi. Nat Toxins. 1992;1:185-196.

20. Shan TJ, Lou JF, Gao S, Zhou YF, Sun WB, Luo C, Zhou L. Antibacterial activity of the endophytic fungi from a traditional Chinese herb Paris polyphylla var. chinensis. Afr J Microbiol Res. 2012;6: 3440-3446

21. Shen $X Y$, Cheng YL, Cai CJ, Fan L, Gao J, Hou CL. Diversity and antimicrobial activity of culturable endophytic fungi isolated from moso bamboo seeds. Plos One. 2014;9:e95838.

22. dos Santos IP, da Silva LCN, da Silva MV, de Araújo JM, Cavalcanti MD, Lima VLD. Antibacterial activity of endophytic fungi from leaves of Indigofera suffruticosa Miller (Fabaceae). Front Microbiol. 2015:6: 350.

23. Radić N, Štrukelj B. Endophytic fungi - the treasure chest of antibacterial substances. Phytomedicine. 2012;19:1270-1284.

24. Deshmukh SK, Verekar SA, Bhave SV. Endophytic fungi: a reservoir of antibacterials. Front Microbiol. 2014;5:715.

25. Kharwar RN, Gond SK, Kumar A, Mishra A. A comparative study of endophytic and epiphytic fungal association with leaf of Eucalyptus citriodora Hook., and their antimicrobial activity. World J Microbiol Biotechnol. 2010;26:1941-1948.

26. Miljkovic A, Mantle PG, Williams DJ, Rassing, B. Scorpinone: a new natural azaanthraquinone produced by a Bispora-like tropical fungus. J Nat Prod. 2001;64:1251-1253.

27. Parisot D, Devys M, Barbier M. Notizen: 5-Deoxybostrycoidin, a new metabolite produced by the fungus Nectria haematococca (Berk. and Br.) Wr. Z Naturforsch B Chem Sci. 1989;44:1473-1474.

28. Ouyang JK, Wu CY, Wang YY, Zhang CB, Mao ZL, Shan TJ. Isolation and identification of active ingredients produced by endophytic fungus Chaetomium sp. Eef-10 from Eucalyptus exserta. J South Chin Agric Univ. 2020;41:104-110.

29. Mao ZL, Xue MY, Gu G, Wang, WX, Li DP, Lai DW, Zhou LG. Lophiostomin A-D: new 3, 4-dihydroisocoumarin derivatives from the endophytic fungus Lophiostoma sp. Sigrf10. RSC Adv. 2020;10:6985-6991.

30. Ismail, Muhammad H, Hussain A, Iqbal A, Khan SA, Khan MA, Lee IJ. An Endophytic fungus Gliocladium cibotii regulates metabolic and antioxidant system of Glycine max and Helianthus annuus under heat stress, Pol J Environ Stud. 2021;30:1631-1640.

31. Ali R, Gul H, Hamayun M, Rauf M, lqbal A, Shah M, Hussain A, Bibi H, Lee IJ. Aspergillus awamori ameliorates the physicochemical characteristics and mineral profile of mung bean under salt stress. Chem Biol Technol Agric. 2021;8:9.

32. Mehmood A, Hussain A, Irshad M, Hamayun M, labal A, Tawab A, Khan N. Yucasin and cinnamic acid inhibit IAA and flavonoids biosynthesis minimizing interaction between maize and endophyte Aspergillus nomius. Symbiosis. 2020; 81:149-160.

33. Miguel PSB, Delvaux JC, Oliveira MNV, Moreira BC, Borges AC, Totola MR, Neves JCL, Costa MD. Diversity and distribution of the endophytic fungal community in eucalyptus leaves. Afr J Microbiol Res. 2017;11:92-105.

34. Shan TJ, Qin K, Xie YY, Zhang WH, Mao ZL, Wang J. Secondary metabolites of endophytic fungi isolated from Casuarina equisetifolia and their bioactivities. J South Chin Agric Univ. 2019;40: 67-74.

35. Guo SX. The recent progress and prospects of research on endophytic fungi in medicinal plants. Microb Biosyst. 2018;37:1-13.

36. Shan TJ, Tian J, Wang XH, Mou Y, Mao ZL, Lai DW, Dai JG, Peng YL, Zhou $L G$, Wang MA. Bioactive spirobisnaphthalenes from the endophytic fungus Berkleasmium sp. J Nat prod. 2014:77: 2151-60.

37. Kaul S, Gupta S, Ahmed M, Dhar MK. Endophytic fungi from medicinal plants: a treasure hunt for bioactive metabolites. Phytochem Rev. 2012;11: 487-505.

38. Kusari S, Pandey SP, Spiteller M. Untapped mutualistic paradigms linking host plant and endophytic fungal production of similar bioactive secondary metabolites. Phytochemistry. 2013;91:81-87.

39. $X u Z Y, W u X, L i G$, Feng $Z, X u J$ J. Pestalotiopisorin $B$, a new isocoumarin derivative from the mangrove endophytic fungus Pestalotiopsis sp. HHL101. Nat Prod Res. 2020;34:1002-1007.

40. Yang BY, Tong QY, Lin S, Guo JR, Zhang JW, Liu JJ, Wang JP, Zhu HC, Hu ZX, Zhang YH. Cytotoxic butenolides and diphenyl ethers from the endophytic fungus Pestalotiopsis sp. Phytochem Lett. 2019;29:186-189. 
41. Cui JL, Guo SX, Dong H, Xiao P. Endophytic fungi from dragon's blood specimen: isolation, identification, phylogenetic diversity and bioactivity. Phytother Res. 2011;25:1189-1195.

42. Hashimoto A, Hirayama K, Takahashi H, Matsumura M, Okada G, Chen CY, Huang JW, Kakishima M, Ono T, Tanaka K. Resolving the Lophiostoma bipolare complex: Generic delimitations within Lophiostomataceae. Stud Mycol. 2018;90:161-189.

43. Koyama J, Morita I, Kobayashi N, Osakai T, Usuki Y, Taniguchi M. Structureactivity relations of azafluorenone and azaanthraquinone as antimicrobial compounds. Bioorg Med Chem Lett. 2005;15:1079-1082.

44. Van Wagoner RM, Mantle PG, Wright JLC. Biosynthesis of scorpinone, a 2azaanthraquinone from Amorosia littoralis, a fungus from marine sediment. J Nat Prod. 2008;71:426-430.

45. Toledo AV, Franco MEE, Lopez SMY, Troncozo MI, Saparrat MCN, Balatti PA. Melanins in fungi: Types, localization and putative biological roles. Physiol Mol Plant Pathol. 2017; 99:2-6.

46. Frandsen RJN, Rasmussen SA, Knudsen PB, Uhlig S, Petersen D, Lysøe E, Gotfredsen $\mathrm{CH}$, Giese $\mathrm{H}$, Larsen TO. Black perithecial pigmentation in Fusarium species is due to the accumulation of 5-deoxybostrycoidin-based melanin. Sci Rep. 2016;6:26206.

47. Studt, L, Wiemann P, Kleigrewe K, Humpf HU, Tudzynski B. Biosynthesis of fusarubins accounts for pigmentation of Fusarium fujikuroi perithecia. App Environ Microbiol. 2012;78:4468-4480

48. Dadachova E, Bryan RA, Howell RC, Schweitzer AD, Aisen P, Nosanchuk JD, Casadevall A. The radioprotective properties of fungal melanin are a function of its chemical composition, stable radical presence and spatial arrangement. Pigm Cell Melanoma Res. 2008;21:192-199.

49. Gaffoor I, Brown DW, Plattner R, Proctor RH, Qi W, Trail F. Functional analysis of the polyketide synthase genes in the filamentous fungus Gibberella zeae (anamorph Fusarium graminearum). Eukaryot Cell. 2005;4:1926-1933.

50. Cambaza E. Comprehensive description of Fusarium graminearum pigments and related compounds. Foods. 2018;7:165.

51. Cui H, Yu J, Chen S, Ding M, Huang X, Yuan J, She Z. Alkaloids from the mangrove endophytic fungus Diaporthe phaseolorum SKS019. Bioorg Med Chem Lett. 2017;27:803-807.

52. Zhong LY, Zou L, Tang XH, Li WF, Li X, Zhao G, Zhao JL. Community of endophytic fungi from the medicinal and edible plant Fagopyrum tataricum and their antimicrobial activity. Trop J Pharm Res. 2017;16:387-396.

53. Xu LJ, Wang JH, Zhao JL, Li PQ, Shan TJ, Wang JG, Li XL, Zhou LG. Beauvericin from the endophytic fungus, Fusarium redolens, isolated from Dioscorea zingiberensis and its antibacterial activity. Nat Prod Commun. 2010;5:811-814.

54. Zaman AU, Ahmad I, Pervaiz M, Ahmad S, Kiran S, Khan MA, Gulzar T, Kamal T. A novel synthetic approach for the synthesis of pyrano[3,2-c] quinolone3 carbaldehydes by using modified Vilsmeier Haack reaction, as potent antimicrobial agents. J Mol Struct. 2019;1180:227-236.

\section{Publisher's Note}

Springer Nature remains neutral with regard to jurisdictional claims in published maps and institutional affiliations.

Ready to submit your research? Choose BMC and benefit from:

- fast, convenient online submission

- thorough peer review by experienced researchers in your field

- rapid publication on acceptance

- support for research data, including large and complex data types

- gold Open Access which fosters wider collaboration and increased citations

- maximum visibility for your research: over $100 \mathrm{M}$ website views per year

At BMC, research is always in progress.

Learn more biomedcentral.com/submissions 